\title{
Image-Based Modelling of Cardiac Mechanics
}

\author{
Mais O. Al-Saffar ${ }^{1}$, Ziad T. Al-Dahhan ${ }^{2}$, Rafid B. Al-taweel ${ }^{3}$
}

\section{Authors affiliations:}

1) Dept. of Biomedical Eng., AlNahrain University, Baghdad-Iraq. mais.o.abdulrassul@,ced.nahrainuni v.edu.iq

2) Dept. of Biomedical Eng., AlNahrain University, Baghdad-Iraq. ziad.t.mahmood@,ced.nahrainuniv. edu.iq

3) Dept. of Internal Medicine, AlNahrain University, Baghdad-Iraq. drrafid76@,colmed-alnahrain.edu.iq

\section{Paper History:}

Received: 24th April. 2021

Revised: $5^{\text {th }}$ Oct. 2021

Accepted: $4^{\text {th }}$ Nov. 2021

\begin{abstract}
The main objective of this study was to model the left ventricle (LV) based on 2D echocardiography imaging technique to assess the cardiac mechanics for group of patients affected by heart failure. A prospective study has been made at Ibn Al-Bitar center for cardiac surgery, for 13 patients with heart failure (HF), 9 patients were males $(69 \%)$ and 4 females (31\%). The mean age was $54 \pm 7$ years. Those patients were supposed to undergo a CRT-D (Cardiac Resynchronization Therapy Defibrillator) implant as they didn't respond to drug therapy. Before CRT-D implantation, 2D echocardiography was performed for all the patients, to model the left ventricle and to measure indices that were used to evaluate cardiac mechanics which are LV pressure, wall stresses, global longitudinal strain, and cardiac output. After 3-months of follow-up, 2D echocardiography was re-assessed and the left ventricular mechanics has been re-measured. Post CRT-D implantation, significant improvement in the cardiac mechanics was observed in $54 \%$ of the patients which were called responders (patients that respond to CRT$\mathrm{D}$ device) and the other patients were called non-responders. It has been seen that, the circumferential wall stresses were decreased in responder's group while increased or remain unchanged in nonresponders. Global longitudinal strain for the responder's group were increased while remain unchanged in the non-responders. So, patients were divided into responders and non-responders, based on improvement of the cardiac mechanics after 3-moths of follow up. It has been concluded that the modelling of the left ventricle based on images obtained from 2D echocardiography imaging techniques, was an important computational tool that was used to enhance understanding and support the evaluation, surgical guidance and treatment management of basic biophysics underlying cardiac mechanics.
\end{abstract}

Keywords: Cardiac Mechanics, Heart Failure, CRT-D, 2D, Echocardiography, Modelling.

$$
\begin{aligned}
& \text { النمذجة القائمة على الصورة لميكانيكية القلب }
\end{aligned}
$$

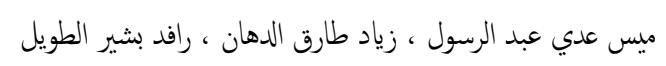

$$
\begin{aligned}
& \text { كان الهدف الرئيسي من هذه الدراسة هو نمذجة البطين الأيسر (LV) بناءً على تقنية تصوير تخطيط }
\end{aligned}
$$

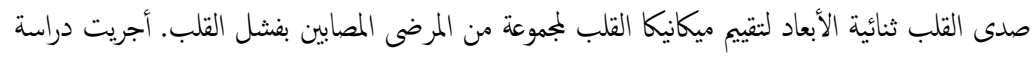

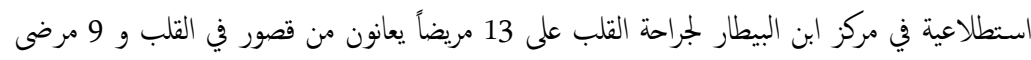

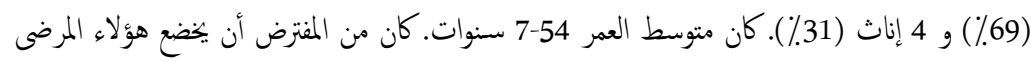

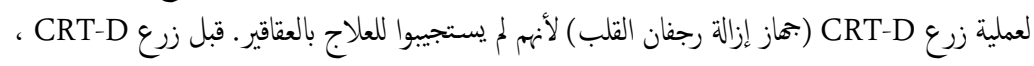

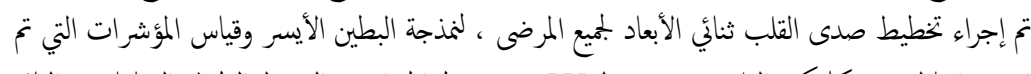

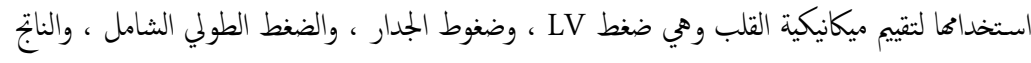




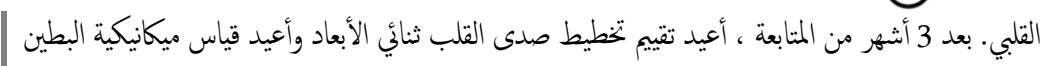

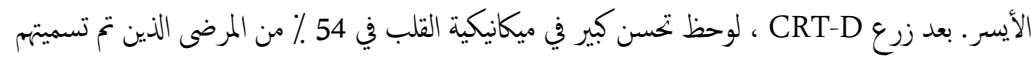

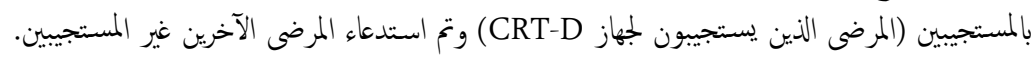

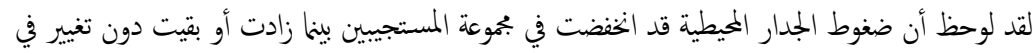

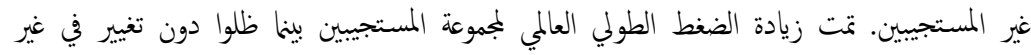

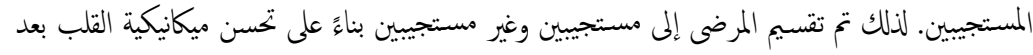

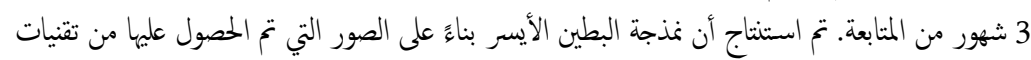

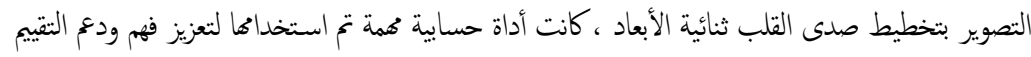

$$
\begin{aligned}
& \text { والتوجيه الجراحي وإدارة العلاج للفيزياء الحيوية الأساسية الكامنة وراء ميكانيكية القلب. }
\end{aligned}
$$

\section{Introduction}

The development of patient-specific (PS) cardiac models is increasing exponentially in order to reach highly detailed description of anatomy and mechanical simulation of the organ. This is growing in parallel with computational tools, becoming day-by-day more and more sophisticated.

Cardiovascular structure and function measurements can be implemented using advanced computer techniques to study myocardial function and dysfunction processes and can contribute to clinical diagnosis and to the development of customized treatment. Image-based simulation models will enhance understanding and support the evaluation, surgical guidance and treatment management of basic biophysics underlying cardiac mechanics.

A coordinated effort is needed both from clinical imaging and modelling communities for addressing the challenges in the field.

In an in vivo tissue properties and regional mechanical activities (e.g., pressure, stresses and strains) were assessed using recent developments in medical imaging, modelling techniques and computational infrastructure, using ventricular geometry measurements, wall deformation and loading conditions. As it is able to assist in stratifying different forms of heart failure, gaining an understanding of the causes of $\mathrm{HF}$ and informing mechanical therapy design, the clinical community is very involved in research into an in vivo assessment of the mechanical function of tissues [1].

In cardiovascular medicine, a noninvasive regional myocardial function assessment is used in the diagnosis of disorders, therapeutic assessment and clinical performance. Echocardiography is currently the widest-used procedure for clinical practice because of portability, low risk and high temporal precision, whereas MRIs and CTs are also diagnostic methods that are useful [2]. Different LV walls stress models were designed to characterize LV mechanics and compute stress models such as Laplace law thin-wall models, thick-wall shell models and finite element models [3]. Most of the latest LV remodeling models, with the help of idealistic spherical, spheroidal, and ellipsoidal geometries, have been developed. While finite element models provide a certain degree of flexibility in the LV geometry, they require high computational power. The interplay between LV stress and strain and between remodeling and geometric development was not determined on a lifetime basis.

\section{Methods}

\section{$>$ Basic Model of the Left Ventricle}

a. Left Ventricular Stress

According to Sandier and Dodge [4], the left ventricle was thought to be approximated by a thinwalled ellipsoid, and a modified form of LaPlace equation [5] in the form where $\sigma_{1}$ and $\sigma_{2}$ are the circumferential and meridional stresses, $R_{2}$ and $R_{1}$ are the radii of curvature respectively, $p$ is the pressure and $\mathrm{h}$ is the wall thickness. Using this equation

$$
\frac{\mathrm{P}}{\mathrm{h}}=\frac{\sigma_{1}}{\mathrm{R}_{1}}+\frac{\sigma_{2}}{\mathrm{R}_{2}}
$$

Then, using the assumptions listed below, two formulae for meridional and circumferential wall stresses at the equator were expanded:

(1) that the ventricle is homogeneous and isotropic, (2) that the wall's stress remains constant (a constant stress across the wall implies that there are no shear forces and bending moments), and

(3) most important, that the wall stresses act only at the inner surface. The equations for equatorial stresses are as follows:

$$
\begin{aligned}
\sigma_{1} & =\frac{\mathrm{PR}_{2}{ }^{2}}{\mathrm{~h}\left(2 \mathrm{R}_{2}+\mathrm{h}\right)} \\
\sigma_{2} & =\frac{\mathrm{Pb}}{\mathrm{h}}\left[1-\frac{\mathrm{b}^{3}}{\mathrm{a}^{2}(2 \mathrm{~b}+\mathrm{h})}\right]
\end{aligned}
$$

where $\mathbf{a}$ is the major semi-axis and $\mathbf{b}$ is the minor semiaxis. Equation (3) is erroneous, since $\sigma_{1}$ should equal $\sigma_{2}$ for the limiting case of a sphere $(\mathrm{a}=\mathrm{b})$, and such is not the case except in the limiting case where $h<<$.

The method employs one or other of two wellestablished three-dimensional internal $(I)$ left ventricular geometric shapes using a combination of the area perpendicular to the long-axis at the level of the mitral valve and length (L) of long-axis to determine internal left ventricular volume [6].

Figure (1) is a schematic diagram of the left ventricle that is used in the model to calculate internal (I) and external (E) volumes during diastole from the short-axis diameter/width $\left(\mathrm{IW}_{\mathrm{d}} \& \mathrm{EW}_{\mathrm{d}}\right)$ and long-axis length $\left(\mathrm{IL}_{\mathrm{d}} \& \mathrm{EL}_{\mathrm{d}}\right)$. The apex, base, endocardium and epicardium are labelled. The diastolic external and internal volumes are calculated and the myocardial volume obtained from the difference. The external 
short-axis width and length are reduced to simulate systole $\left(\mathrm{EW}_{\mathrm{s}} \& \mathrm{EL}_{\mathrm{s}}\right.$, respectively) and the new external volume calculated. The internal end-systolic volume is calculated by subtracting the muscle volume from the external end-systolic volume. If one assumes that the external (E) left ventricular volume is a similar shape to the internal volume then total or external left ventricular volume can be calculated using the same formula [6].

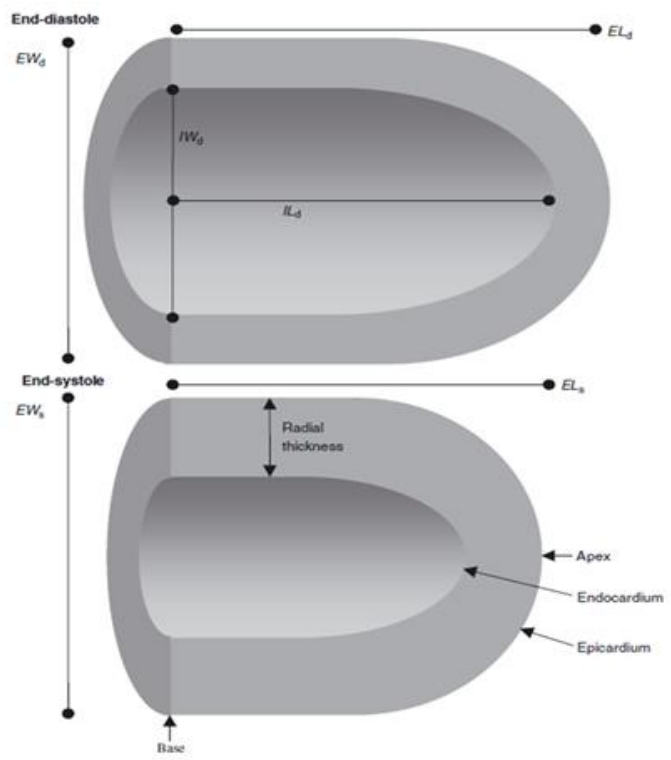

Figure (1): Schematic diagram of the left ventricle [6].

The total myocardial volume is derived from the difference in total (external) left ventricular volume and the internal volume as seen in Figure (1). Two different formulae are available and each assumes a slightly different geometry of the left ventricle [6]:

(a) Area-length method of Dodge

$$
V=\frac{\pi}{6} W^{2} \cdot L
$$

where $\boldsymbol{V}=$ volume, $\boldsymbol{W}=$ width (i.e. short-axis diameter), $L=$ long-axis length.

So,

$$
\begin{aligned}
& \text { External volume in diastole }=\frac{\pi}{6} E W_{d}{ }^{2} \cdot E L_{d} \ldots \text { (5) } \\
& \text { Internal volume }=\frac{\pi}{6} I W_{d}{ }^{2} \cdot I L_{d}
\end{aligned}
$$

Myocardial volume $=$ External volume-Internal volume

(b) Hemi-cylinder-hemi-ellipsoidal method

$$
V=\frac{5 \pi}{6} \cdot \frac{W^{2}}{2} \cdot L
$$

It is theoretically possible to assess the stress on the wall in all directions and as a function of position given the real three-dimensional structure and transmural pressure. Since this is a complicated computational problem in general, a series of conventions has been created to make stress calculation both easier and more practical [7].
End-systolic circumferential wall stress $\left(\sigma_{\mathrm{c}}\right)$ was calculated by using the following equation:

$$
\begin{aligned}
& \sigma_{c}=\text { LVPes } \times(0.5 \text { LVIDs })^{2} \times \\
& \frac{\left\{\left[1+\frac{(0.5 \mathrm{LVIDs}+\mathrm{PWTs})^{2}}{(0.5 \mathrm{LVIDs}+0.5 \mathrm{PWTs})^{2}}\right.\right.}{(0.5 \mathrm{LVIDs}+\mathrm{PWTs})^{2}-(0.5 \mathrm{LVIDs})^{2}}
\end{aligned}
$$

Where, LVPes is estimated end-systolic LV pressure, LVIDs is the LV end systolic diameter, PWTs is the end-systolic posterior wall thickness [8]. LVPes is end-systolic LV pressure estimated from the mean arterial pressure (MAP) using blood pressure (BP) measured by brachial cuff as follows [9]:

$\mathrm{MAP}=\frac{\text { Systolic BP+2(diastolic BP })}{3}$

$$
\text { LVPes }=\text { MAP }+7
$$

The ability of the heart to generate pressure by muscle contraction is referred to as efficiency. This efficiency is often referred to as the demand placed on the muscle by the body's need to maintain pressure. The stress peak happens early in ejection and then drops even as LV pressure rises, indicating an increasingly efficient geometry as the heart contracts [7].

\section{b. Global Peak Longitudinal Strain (GLS)}

A groundbreaking approach for 2D strain analysis was introduced as follows: digital loops were acquired from apical 2-, 3-, and 4-chamber views from 2D echocardiography and a line was loosely traced along the LV endocardium at the frame wherein it was better described as shown in Figure (2), A.

On the basis of this line, a region of interest was generated a seen in Figure (2), B and length of the region of interest was calculated by using image $\mathrm{J}$ software. The GLS was measured for the entire Ushaped length of the LV myocardium (basal, mid, and apical parts of two opposite walls in each view) (Figure 2), whereas

$$
\begin{gathered}
\mathrm{GLS} \%=\frac{\mathrm{L} \text { (end_systole) }-\mathrm{L} \text { (end_diastole) }}{\mathrm{L}(\text { end_diastole })} \times 100 \% \\
\ldots \ldots(12)
\end{gathered}
$$

where $\mathrm{L}$ denotes the length of the interest [10].

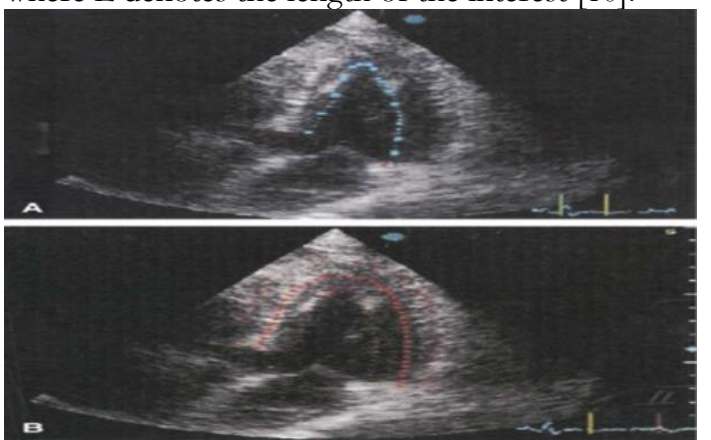

Figure (2): At the frame where it is best defined, a line is loosely drawn along the left ventricular endocardium (A). U-shaped line was drawn, which includes the basal, mid, and apical segments of two opposing walls (B) $[10]$.

Longitudinal, radial, circumferential, and rotational strains or deformations have been identified in myocardial regional mechanics as measured by 
echocardiographic approaches as seen in Figure (3) [11].

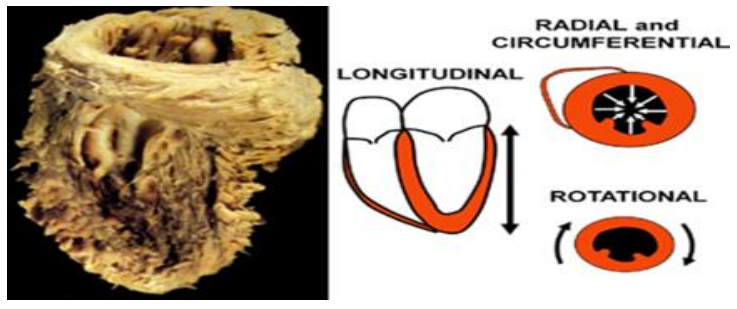

Figure (3): The Principal Vectors of Left Ventricular Strain and Myocardial Fiber Orientation (Echocardiographic application of strain imaging has assessed longitudinal strain from apical windows and radial, circumferential, and rotational strain from parasternal windows) [11].

Despite the fact that myocardial fiber orientation causes these strain vectors to appear in three dimensions and in an integrated manner, the majority of research has relied on individual strain evaluations [11].

\section{c. Stroke Volume and Cardiac Output}

The heart's function can be measured using a number of different parameters. However, since the heart's primary function is to pump blood across the body, the most useful measurements are those that calculate the total amount of blood pumped. The difference between the LV volume at end-diastole (EDV) and end-systole (ESV) is known as stroke volume (SV) [12]:

$$
\mathrm{SV}=\mathrm{LVEDV}-\mathrm{LVESV}
$$

Where LVEDV is LV volume in end-diastole and LVESV is LV volume in end-systole.

If resting stroke volume is relatively fixed at the lowest level that can allow tissue perfusion and maintain blood pressure then it is not surprising that stroke volume in heart failure remains relatively normal. The only way this can be achieved is by increasing end-diastolic volume [13].

Cardiac output (CO) is the amount of blood pumped every minute by the heart.

$$
\mathrm{CO}=\mathrm{SV} \times \mathrm{HR}
$$

HR stands for heart rate. $\mathrm{CO}$ is a key indicator of overall heart function. $\mathrm{CO}$ increases as the body's demand rises, such as during physical exercise. CO is influenced by a number of factors, one of which is myocardial contractility [12].

\section{D Echocardiography}

In the clinical routine setting, ultrasound is commonly used to measure heart function, and a variety of echocardiographic procedures were used to determine cardiac function. Originally, the evaluation of ultrasonic cardiac function was mostly dependent on visual interpretation of myocardial motion in $2 \mathrm{D}$ gray-scale images in various imaging planes. A commercially available technology was used to image patients in the left lateral decubitus position (Vingmed system Seven, General Electric-Vingmed) at a depth of $16 \mathrm{~cm}$ in the parasternal and apical views using a $1.713 \mathrm{MHz}$ transducer (standard long-axis, 2- and 4chamber images). Cine-loop format was used to save standard 2-dimensional and color Doppler data triggered by the QRS complex. From the conventional apical 2- and 4-chamber images, the LV volumes (endsystolic, end-diastolic) and LV ejection fraction were measured [14].

All echocardiographical data have been offline analyzed using commercial applications (Echopac 4.0.3, General Electric). Figure (4) shows many of the most common ultrasonic scan planes, namely the 4chamber apical view $(4 \mathrm{CH})$, the 2-chamber apical view $(2 \mathrm{CH})$, the APLAX or $3 \mathrm{CH}$ long-axis view (APLAX or $3 \mathrm{CH}$ ), and the heart transverse plane (also referred to as the short-axis parasterial view) [15].

The transducer is positioned between two ribs apically in order to acquire $4 \mathrm{CH}, 3 \mathrm{CH}$ and $2 \mathrm{CH}$ [15]. Gray-scale ultrasound images from all of these projections are seen in Figure (5).

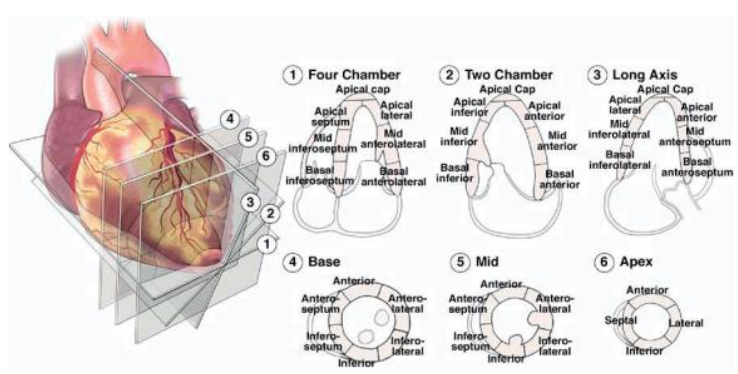

Figure (4): The heart's imaging planes are described. Based on schematic views, a segmental analysis of the left ventricular walls was performed. The apical longaxis views are seen in the upper figures: four-chamber view $(4 \mathrm{CH})$, two-chamber view $(2 \mathrm{CH})$, and apical long-axis view $(3 \mathrm{CH})$. The short-axis views of the heart at the basal, mid, and apical levels are shown in the lower figures [16].
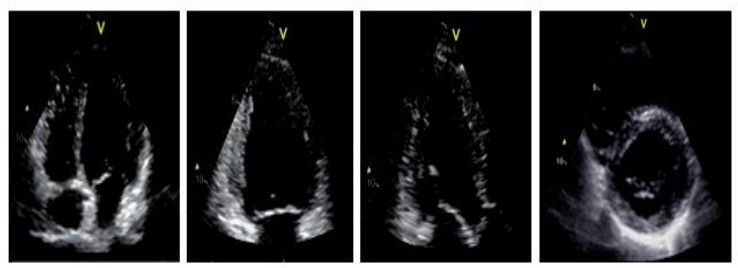

Figure (5): Gray-scale ultrasound images of the heart. Apical four-chamber view $(4 \mathrm{CH})$, apical two-chamber view $(2 \mathrm{CH})$, apical long-axis view $(3 \mathrm{CH})$, and a shortaxis view at the basal level of the heart are seen from left to right [15].

M-mode echocardiography of the left ventricle is as shown in Figure (6).

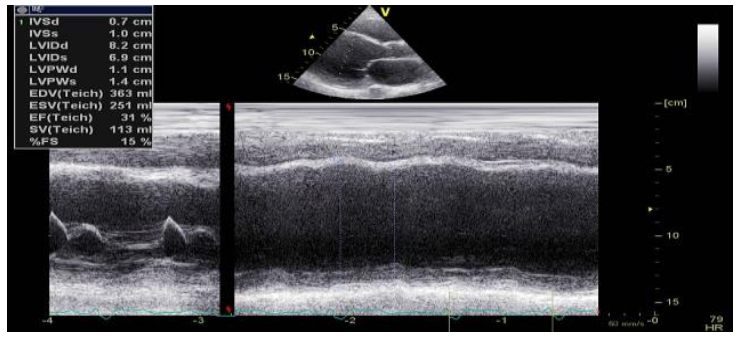


Figure (6): M-mode left ventricle echocardiography, displaying the measurements and function of the LV, (IVSD): Interventricular Septum Thickness in $\mathrm{cm}$ at End Diastole, (IVSS):Interventricular Septum Thickness in $\mathrm{cm}$ at End systole, (LVIDd) : Left Ventricular Internal Diameter in $\mathrm{cm}$ at End Diastole, (LVIDs):Left Ventricular Internal Diameter in $\mathrm{cm}$ at End systole, (LVPWd):Left Ventricular Posterior Wall Thickness in $\mathrm{cm}$ at End Diastole, (LVPWs): Left Ventricular Posterior Wall Thickness in $\mathrm{cm}$ at End systole, (EDV):End Diastolic Volume in $\mathrm{ml}$, (ESV):End Systolic Volume in $\mathrm{ml}$, (LVEF):Left Ventricular Ejection Fraction (\%), (SV): Stroke Volume (ml), (FS): Fractional Shortening (\%).

\section{Statistical analysis}

Statistical analyses were performed using SPSS software version 22. Results are expressed as percent for categorical variables and mean \pm standard deviation for numerical variables. Data were compared with paired or unpaired Student's t test when appropriate. Enhancement in the cardiac mechanics was examined by comparing baseline vs. follow-up parameters using Student's paired t-test for comparisons of quantitative variables. For all tests, a p value $<0.05$ was considered statistically significant.

\section{Results}

\section{$>$ Cardiac Mechanics Evaluation}

Indices used to evaluate left ventricular (LV) performance in clinical practice (LV pressure, circumferential wall stress at end systole, global longitudinal stain and cardiac output) are usually used to assess the cardiac mechanics in patients with heart failure. These indices are measured pre and post CRT$\mathrm{D}$ for all patients, it has been seen that wall stresses were decreased in responder's group while increased or remain unchanged in non-responders. Global longitudinal strain for the responder's group were increased while remain unchanged in the nonresponders. The measurements of these indices were based on the echocardiography images of the patients as shown in table (1) for pre-CRT-D and table (2) for post CRT-D.

Table (1): The values of pressure, stress, strain and cardiac output for all patients in pre- CRT-D.

\begin{tabular}{|c|c|c|c|c|}
\hline Patient & $\begin{array}{c}\text { Pressure } \\
(\mathrm{mm} \mathrm{Hg})\end{array}$ & $\begin{array}{c}\text { Stress } \\
\left(\mathrm{Kdyne} / \mathrm{cm}^{2}\right)\end{array}$ & $\begin{array}{c}\text { Strain } \\
(\%)\end{array}$ & $\begin{array}{c}\text { Cardiac } \\
\text { Output } \\
(\mathrm{L} / \mathrm{min})\end{array}$ \\
\hline 1 & 90.33 & 292.4 & -5.6 & 9.1 \\
\hline 2 & 107 & 341.2 & -5.4 & 4 \\
\hline 3 & 87 & 136.1 & -11.8 & 6.2 \\
\hline 4 & 90.33 & 339.7 & -4.6 & 7.2 \\
\hline 5 & 90.33 & 307.32 & -7.1 & 7 \\
\hline 6 & 80.33 & 143.1 & -7.1 & 7 \\
\hline 7 & 83.33 & 87.1 & -16 & 11.5 \\
\hline 8 & 93.67 & 219.3 & -7.6 & 4.6 \\
\hline 9 & 103.67 & 265.82 & -5.6 & 10.9 \\
\hline 10 & 97 & 427.3 & -11.7 & 9 \\
\hline 11 & 100.33 & 278.33 & -5 & 6.5 \\
\hline 12 & 87 & 261.1 & -5.5 & 2.9 \\
\hline 13 & 87 & 246.1 & -8.1 & 4.7 \\
\hline
\end{tabular}

Table (2): The values of pressure, stress, strain and cardiac output for all patients in post- CRT-D.

\begin{tabular}{|c|c|c|c|c|}
\hline Patient & $\begin{array}{c}\text { Pressure } \\
(\mathrm{mm} \mathrm{Hg})\end{array}$ & $\begin{array}{c}\text { Stress } \\
\left(\mathrm{Kdyne} / \mathrm{cm}^{2}\right)\end{array}$ & $\begin{array}{c}\text { Strain } \\
(\%)\end{array}$ & $\begin{array}{c}\text { Cardiac } \\
\text { Output } \\
(\mathrm{L} / \mathrm{min})\end{array}$ \\
\hline 1 & 113.7 & 676.3 & -6.7 & 8.6 \\
\hline 2 & 103.7 & 303 & -5.1 & 3 \\
\hline 3 & 100.33 & 106.5 & -9.7 & 7.9 \\
\hline 4 & 100.33 & 236 & -3.9 & 9.4 \\
\hline 5 & 107 & 333.1 & -8.3 & 4.8 \\
\hline 6 & 93.67 & 84.44 & -8.7 & 3.2 \\
\hline 7 & 110.33 & 85.2 & -12.7 & 9 \\
\hline 8 & 100.33 & 250.1 & -6.6 & 6.4 \\
\hline 9 & 93.67 & 115.63 & -6.6 & 5.1 \\
\hline 10 & 107 & 392.5 & -3.5 & 7.5 \\
\hline 11 & 110.33 & 116.13 & -12.7 & 5.8 \\
\hline 12 & 97 & 116.26 & -14.3 & 2.8 \\
\hline 13 & 97 & 248 & -5.7 & 6.5 \\
\hline
\end{tabular}

\section{$>$ Statistical Tests}

It is used to define the effect of CRT-D device on the cardiac mechanics for patients with heart failure. Based on the comparison between measured data in pre and post CRT-D, the responders can be defined. Paired samples T-test is used to indicate statistically significant differences between measured data in pre and post CRT-D. It means that these data are related to the same sample's patients which indicates a correlation between them with a significant level $\mathrm{P}$ (0.05).

Table (3): shows a summery for the mean $\pm S D$ and $P$ value for responders and non- responder.

\begin{tabular}{|c|c|c|c|c|c|}
\hline $\begin{array}{l}\text { 3-month } \\
\text { follow-up } \\
\text { results }\end{array}$ & \multicolumn{2}{|c|}{$\begin{array}{l}\text { Responders } \\
(\text { mean } \pm \text { SD) }\end{array}$} & $\begin{array}{c}\text { P } \\
\text { Resp. }\end{array}$ & $\begin{array}{l}\text { Non-resp. } \\
\text { (mean } \pm \text { SD) }\end{array}$ & $\begin{array}{c}\mathrm{P} \\
\text { Non- } \\
\text { resp. }\end{array}$ \\
\hline \multirow{2}{*}{$\begin{array}{c}\mathrm{CO} \\
(\mathrm{L} / \mathrm{min})\end{array}$} & Base & \pm 2.7 & \multirow[b]{2}{*}{.288} & $6.2 \pm 2$ & \multirow[b]{2}{*}{.716} \\
\hline & $\begin{array}{c}\text { Follow } \\
\text {-up }\end{array}$ & $6.2 \pm 2.5$ & & $6.6 \pm .7$ & \\
\hline \multirow{2}{*}{$\begin{array}{c}\text { GLS (Avg) } \\
(\%)\end{array}$} & Base & $-7.9 \pm 4.9$ & \multirow[b]{2}{*}{.335} & $-5.2 \pm 2.8$ & \multirow[b]{2}{*}{.314} \\
\hline & $\begin{array}{c}\text { Follow } \\
\text {-up }\end{array}$ & $-9.6 \pm 3.6$ & & -4.5 & \\
\hline \multirow{2}{*}{$\begin{array}{c}\text { Stress } \\
\left(\mathrm{Kdyne}^{2} /\right. \\
\left.\mathrm{cm}^{2}\right) \\
\end{array}$} & Base & $15.9 \pm 93$ & \multirow[b]{2}{*}{.049} & $305.6 \pm 74$ & \multirow[b]{2}{*}{.789} \\
\hline & $\begin{array}{c}\text { Follow } \\
\text {-up }\end{array}$ & $122.9 \pm 51$ & & $383.8 \pm 151$ & \\
\hline
\end{tabular}

\section{Discussion}

Post CRT-D implantation, significant improvement in the cardiac mechanics was observed in $54 \%$ of the patients which were called responders (patients that respond to CRT-D device) and the other patients were called non-responders. It has been seen that, the circumferential wall stresses were decreased in responder's group while increased or remain unchanged in non-responders. Global longitudinal strain for the responder's group were increased while remain unchanged in the non-responders. So, patients were divided into responders and non-responders, based on improvement of the cardiac mechanics after 3-moths of follow up.

\section{Conclusion}

It has been concluded that the modelling of the left ventricle based on images obtained from 2D echocardiography imaging techniques, was an important computational tool that was used to 
enhance understanding and support the evaluation, surgical guidance and treatment management of basic biophysics underlying cardiac mechanics.

\section{References:}

[1] V. Y. Wang, P. M. F. Nielsen, and M. P. Nash, "Image-Based Predictive Modeling of Heart Mechanics," Annu. Rev. Biomed. Eng., vol. 17, no. 1, pp. 351-383, 2015, doi: 10.1146/annurev-bioeng071114-040609.

[2] D. H. MacIver, "The relative impact of circumferential and longitudinal shortening on left ventricular ejection fraction and stroke volume," Exp. Clin. Cardiol., vol. 17, no. 1, pp. 5-11, 2012.

[3] H. Zahedmanesh, H. Van Oosterwyck, and C. Lally, "Comput Methods Biomech Biomed Engin, A multi-scale mechanobiological model of in-stent restenosis: deciphering the role of matrix metalloproteinase and extracellular matrix changes. 2014; 17 (8): 813-28. doi: 10.1080/10255842.2012. 716830.” Epub, 2012.

[4] H. Sandler and H. T. Dodge, "Left ventricular tension and stress in man," Circ. Res., vol. 13, no. 2, pp. 91-104, 1963.

[5] P. S. de Laplace, "Sur l'action capillaire," Suppl. au livre X, Trait. Mécanique Céleste, vol. 349, 1806.

[6] D. H. MacIver, "A mathematical model of left ventricular contraction and its application in heart disease," vol. 35, pp. 65-86, 2008, doi: 10.2495/9781-84564-096-5/04.

[7] P. A. McHale and J. C. Greenfield, "Evaluation of several geometric models for estimation of left ventricular circumferential wall stress," Circ. Res., vol. 33, no. 3, pp. 303-312, 1973, doi:

10.1161/01.RES.33.3.303.

[8] G. De Simone et al., "Assessment of left ventricular function by the midwall fractional shortening/end-systolic stress relation in human hypertension," J. Am. Coll. Cardiol., vol. 23, no. 6, pp. 1444-1451, 1994.

[9] J. D. Rozich, B. A. Carabello, B. W. Usher, J. M.
Kratz, A. E. Bell, and M. R. Zile, "Mitral valve replacement with and without chordal preservation in patients with chronic mitral regurgitation:

Mechanisms for differences in postoperative ejection performance," Circulation, vol. 86, no. 6, pp. 17181726, 1992, doi: 10.1161/01.cir.86.6.1718.

[10] S. A. Reisner, P. Lysyansky, Y. Agmon, D. Mutlak, J. Lessick, and Z. Friedman, "Global longitudinal strain: A novel index of left ventricular systolic function," J. Am. Soc. Echocardiogr., vol. 17, no. 6, pp. 630-633, 2004, doi: 10.1016/j.echo.2004.02.011.

[11] J. Gorcsan and H. Tanaka, "Echocardiographic assessment of myocardial strain," J. Am. Coll. Cardiol., vol. 58, no. 14, pp. 1401-1413, 2011, doi: 10.1016/j.jacc.2011.06.038.

[12] A. P. Voorhees and H. C. Han, "Biomechanics of cardiac function," Compr. Physiol., vol. 5, no. 4, pp. 1623-1644, 2015, doi: 10.1002/cphy.c140070.

[13] M. J. Lenzen et al., "Differences between patients with a preserved and a depressed left ventricular function: A report from the EuroHeart Failure Survey," Eur. Heart J., vol. 25, no. 14, pp. 1214-1220, 2004, doi: 10.1016/j.ehj.2004.06.006. [14] N. B. Schiller et al., "Recommendations for Quantitation of the Left Ventricle by TwoDimensional Echocardiography," J. Am. Soc. Echocardiogr., vol. 2, no. 5, pp. 358-367, 1989, doi: 10.1016/S0894-7317(89)80014-8.

[15] M. Larsson, "Larsson M. Quantification and Visualization of Cardiovascular Function using Ultrasound (Doctoral dissertation, KTH)." KTH, 2009.

[16] R. M. Lang et al., "Recommendations for chamber quantification: a report from the American Society of Echocardiography's Guidelines and Standards Committee and the Chamber Quantification Writing Group, developed in conjunction with the European Association of Echocardiograph," J. Am. Soc. Echocardiogr., vol. 18, no. 12, pp. 1440-1463, 2005. 